minent place, and one notes with satisfaction that the general trend of the curve continues in a downward direction. Greater provision is likely to be made in the near future for the care of expectant mothers, and the official recognition of an ante-natal state, though somewhat belated, is none the less welcome. Much good work has been done by voluntary agencies in the past, and the linking up of this with the various organisations dealing with child welfare must inevitably tend to a healthier future race.

Some interesting figures are given regarding vaccination returns. It appears that in England and Wales as a whole one-half of the children whose births were registered in I9I2 have been vaccinated, and nearly one-third have been exempted from vaccination by statutory declaration of conscientious objection. When compared with the returns for IgIr, these figures show a percentage reduction of $52 \cdot 3$ to $50 \cdot 1$ in the proportion of children born who are vaccinated. The percentage of children born who were exempted under certificate of conscientious objection increased from $28 \cdot 5$ to $32 \cdot 1$.

Inquiries have been made regarding certain outbreaks of enteric fever supposedly due to the consumption of infected shell-fish. The medical officer of health of a seaport town has repeatedly referred to the danger incurred by persons in collecting shellfish of all sorts from areas obviously contaminated with sewage. While it is difficult in most cases to prove conclusively that an epidemic owes its origin to such a practice, yet, when local authorities have acted as if such were undoubtedly the case, the wisdom of such action has been abundantly shown by the nonrecurrence of the disease.

Progress is constantly being made towards securing purer and more wholesome food for consumption in this country. A careful watch has to be kept at the various ports of entry to prevent so far as possible the import of unsound and even poisonous material. As an instance of what is continually happening it will suffice to quote the following occurrence. During the unloading of a cargo of sugar in the Port of London it was noticed that some of the bags containing the sugar were covered with borax, which had been carried in the same hold and had become loose during the voyage. Samples of this powder were taken, and analysis showed them to contain arsenic in considerable quantities. The whole of the sugar was rebagged, and that portion of it that had already been sent out was recalled for suitable treatment under supervision.

The effect of certain types of waters on lead has again been brought into prominence by an outbreak, extensive though mild, of lead poisoning in an urban district in Yorkshire. The waters most liable to act in this way are acid, peaty supplies, and it is even asserted as conceivable that the treatment applied with a view of destroying the plumbo-solvent properties of the water mav tend in some way to increase the ability of the water to erode the lead. At all events, further investigation is being made, as the case in point has proved a very difficult one to deal with.

More research has been conducted on the subject of ferro-silicon with special reference to possible danger arising from its transport and storage. This substance, of certain percentage compositions, is liable to disintegration in the presence of moisture, and po:sonous gases are given off in quantity sufficient to produce fatal results in human beings. It is suggested thet liability to spontaneous disintegration with evolution of poisonous gases may be related to the amount of aluminium present in the ferro-silicon. Further reports are now issued on ferro-chrome and other ferro-alloys, with special reference to aluminium content.

The work of Prof. Leonard Hill on the effect of open-air and wind in the metabolism of man is referred to. He points out that the physical qualities of the air-heat, moisture, and movement-are of paramount importance to health. The stimulating effect of cool and variable breezes acting on the skin leads to improved health, while a stagnant, windless, over-warm atmosphere tends to depression and diminished vitality. Two new instruments are described-the kata-thermometer and the caleometer-which enable the rate of cooling of the body and the variability of the rate to be measured (see p. 205 of this issue of NATURE). Prof. Hill's researches on the physical condition of the atmosphere have done much to elucidate the problem of "stuffiness," to which so many ailments are undoubtedly due.

\section{THE CARNEGIE INSTITUTION OF WASH-} INGTON AND SCIENTIFIC RESEARCH.

$\mathrm{THE}$ Carnegie Institution of Washington was founded by Mr. Carnegie in 1902, when he gave to a board of trustees an endowment of 2,000,00ol., to which he added 400,000 . in 1907 , and a further $2,000,000 l$. in IgII. The articles of incorporation of the institution declare "that the objects of the corporation shall be to encourage, in the broadest and most liberal manner, investigation, research, and discovery, and the application of knowledge to the improvement of mankind," and already, as the annual reports of the president and the directors of the various departments show, the objects of the institution are being fulfilled admirably.

The trustees have inaugurated and developed three principal agencies to forward the aims of the institution. In the first place, the departments of research attack problems requiring the collaboration of several investigators, special equipment, and continuous effort. A second agency provides means to enable individuals to complete investigations requiring less collaboration and simpler apparatus; while a third division deals with the publication of the results obtained as the result of the work of the first two agencies.

The reports by the president, the directors of the various departments of research, and the executive committee, contained in the I9I4 Year Book, recently received, give full particulars of the financial resources of the institution, and of the activities of its different departments, during the year under review. The Year Book provides convincing evidence of the success of the trustees of the institution in their endeavours to encourage and advance scientific research.

The following table shows the amounts of the grants made by the trustees for the current year, and the purposes to which they are being devoted:-

$\begin{array}{lccccr}\text { Administration } & \ldots & \ldots & \ldots & \ldots & \text { 10,000 } \\ \text { Publication } \ldots & \ldots & \ldots & \ldots & \ldots & 12,000 \\ \text { Division of Publications } & \ldots & \ldots & \ldots & 2,000 \\ \text { Departments of Research } & \ldots & \ldots & \ldots & 138,462 \\ \text { Minor Grants } & \ldots & \ldots & \ldots & \ldots & 21,860 \\ \text { Index Medicus } & \ldots & \ldots & \ldots & \ldots & 2,700 \\ \text { Insurance Fund } & \ldots & \ldots & \ldots & \ldots & 5,000 \\ \text { Reserve Fund } & \ldots & \ldots & \ldots & \ldots & 50,000 \\ & & & & & \\ & \text { Total } & \ldots & \ldots & \ldots & 242,022\end{array}$

The next table shows the departments of scientific investigation to which the larger grants were made for the financial year $19 I_{3}-14$, and the amounts of these grants :-

NO. 2373, VOL. 95] 


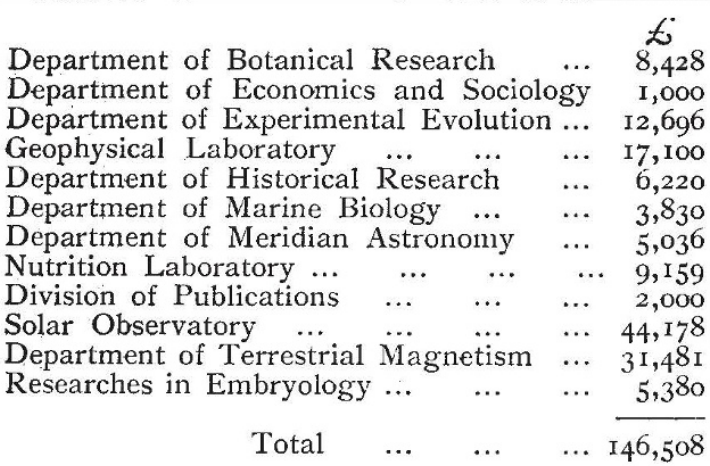

The following extracts from the résumé of the investigations of the year included in the report of the president, Dr. R. S. Woodward, will serve to indicate the nature and extent of the scientific work accomplished during the year.

Although the greater part of the work of the Department of Botanical Research is carried on at its principal laboratory at Tucson, Arizona, it is essential to a comprehensive study of desert plant life to explore distant as well as adjacent arid regions. Thus, having published during the past year the results of an elaborate investigation of the region of the Salton Sea, the department is now turning attention to similar desert basins, of which there are several in the Western States that have been studied hitherto in their geological rather than botanical aspects. These researches are entailing also many applications of the allied physical sciences not heretofore invoked to any marked extent in aid of botanical science. Hence there results properly a diversity of work quite beyond the implications of botany in the earlier, but now quite too narrow, sense of the word. The facilities of the Desert Laboratory have been enlarged during the year by the completion and equipment of a specially designed small building for studies in phyto-chemistry, which has been proved to play a highly significant rôle in desert life.

The observational, statistical, and physical methods applied by the Department of Experimental Evolution are constantly adding to the sum of facts and of inductions essential to advances in biological knowledge. The range of application extends from the lowest organisms, like fungi, up to the highest, as typified in the race to which the investigators themselves belong. Thus, during the past year, observations and experiments have been made on mucors, plants, pigeons, poultry, and seeds, while the director has continued his fruitful statistical studies in the relatively new field of departures from normality in mankind. The variety of agencies employed in this wide range of inquiry now includes a permanent staff of about twenty members and a physical equipment enlarged during the year by the completion of an additional laboratory and a power-house. Early in the year the facilities of the department were increased by the successful transfer, from Chicago to Cold Spring Harbour, of the remarkable collection of pedigree pigeons recently acquired by the institution from the estate of Prof. C. O. Whitman.

An instructive example of the favourable progress, which may be confidently expected in any field of research when entered by an adequately manned and equipped department devoted solely thereto, is afforded by the experience of the Geophysical Laboratory. In less than a decade this establishment has not only accomplished the formidable task of constructing the recessary apparatus and of preparing many of the pure minerals concerned, but has already begun the processes of analysis and synthesis which are leading to extensive additions to our knowledge of rock and mineral formations found in the earth's crust. Among the problems under investigation, one of immediate economic as well as of great theuretical interest may be cited here by reason especially of the fact that funds for its execution have been supplied by industrial sources; this is the problem of the "secondary enrichment of copper ores," and the success attained in its treatment demonstrates the practicability of advantageous co-operation between the laboratory and industrial organisations without restriction to scientific procedure and publicity. The section of the director's report devoted to this subject should be of special interest to geologists and to mining engineers as well as to copper-mining industries. A more comprehensive idea of the productive activities of the laboratory may be gained from its publications, which embrace forty-nine titles of papers which have appeared in current journals or are in the press, many of them having been published in German as well as in English.

In accordance with plans recommended by the director of the Department of Marine Biology and approved by the trustees in I9I2, an expedition to Torres Straits, Australia, was undertaken in the latter part of the preceding year. Early in September, I9I3, the director and six collaborators arrived at Thursday Island in the Straits, expecting to use this relatively accessible island as a base of explorations; but it was soon found advantageous to proceed to Maër Island, one of the Murray group, about 120 miles east-northcast, and near to the outer limit of the Great Barrier Reef. Here a temporary laboratory was set up in the local courthouse and jail, generously placed at Dr. Mayer's disposal by the British authorities. The region proved to be one rich in coral reefs and in marine fauna for the work contemplated. Observations and experiments securing gratifying results were carried out during the months of September and October, I9I3. In addition to the critical data secured by Dr. Mayer with respect to the corals about Maër Island, for comparison especially with corresponding data from the corals of Florida waters, observations and materials for important contributions to zoology were collected by each of his collaborators. On returning to America from the southern hemisphere, the director was engaged, during April and May, in two minor expeditions with the departmental vessel Anton Dohrn. The first of these. was in aid of the researches of Dr. Paul Bartsch, on cerions, and required a cruise along the Florida Keys from Miami to Tortugas and return. The second expedition was in aid especially of Dr. T. W. Vaughan, long associated with the department in studies of corals and related deposits, and required a cruise from Miami, Florida, to the Bahamas and return. It appears that during its first decade forty-nine investigators have made use of the Tortugas Laboratory, twenty-eight of these having returned two or more times, making a total of 108 visits to this relatively inaccessible centre of research. Of the publications emanating from the department, sixty have been published by the institution, while upwards of forty have been published under other auspices.

The activities of the Department of Meridian Astrometry are concentrated on the derivation of stellar positions for the comprehensive catalogue in preparation, on supplementary measurements of stellar coordinates with the meridian circle of the Dudley Observatorv, and on investigations of residual stellar motions. The latter have now become the most important element in the definition of stellar positions by reason of the extraordinary recent progress in sidereal astronomy, to which the department has contributed in large degree. Thus, along with the formNO. 2373, VOL. 95] 
idable computations required by the large mass of observations made by the department at San Luis, Argentina, researches are simultaneously continued on the problems of star-drift, including the speed and direction of motion of our solar system. In the meantime, the catalogue is progressing favourably and some portions of the observatory list of miscellaneous stars are approaching completion, although cloudiness during the past two winters has interfered with this part of the departmental programme. In the meantime, also, the manuscript of the zone catalogue of stars the positions of which were measured at the observatory during the years 1896 to 1900 , is undergoing the final process of comparison and checking preparatory to publication.

The anticipations of a specially favourable environment, which were entertained when the Nutrition Laboratory was located in Boston near the Harvard Medical School and near several existing and projected hospitals, are now fully realised; and it would appear that the laboratory is reciprocally advantageous to the several establishments with which it is in immediate contact. Indeed, with this, as with all other departments of research founded by the institution, the only fears to be entertained seriously are those due to increasing capacity for usefulness and scientific progress, since such capacity tends quite properly to grow faster than the institution's income warrants.

Improvements have been made in the laboratory itself, and several additions to equipment have been installed. These latter include new respiration apparatus for studies of metabolism in muscular work of men and of small animals, a reconstruction of an earlier form of bed calorimeter, and additional apparatus for photo-electric registration of physiological action in subjects under observation, whether near by or at a distance.

As indicated in previous reports, the laboratory and its work are subjects of international as well as national interest, and many co-operative efforts are arising therefrom. Among the researches in progress by the laboratory staff, attention may be directed particularly to "The gaseous metabolism of infants with special reference to its relation to pulse-rate and muscular activity," by Francis G. Benedict and Fritz B. Talbot, and to " A study of prolonged fasting," by Francis G. Benedict.

The extensive operations of the Department of Terrestrial Magnetism on the oceans and in foreign countries have been adequately supplemented during the year by the new departmental laboratory, the completion and occupation of which took place nearly simultaneously with the beginning of the second decade of the department's existence. This laboratory and its site provide greatly enlarged facilities for research, as well as unsurpassed quarters for the resident departmental staff.

Near the end of the preceding year the non-magnetic ship Carnegie returned to New York City, where she underwent such extensive repairs as are always required by wooden vessels after long cruises in tropical waters. After refitting, she left New York, June 8, I014, for a cruise in the North Atlantic. In this. the third of her expeditions, she traversed about ro,6oo miles, making a first stop at Hammerfest, Norway, July 3 , reaching the high latitude $79^{\circ} .5^{2}$ off the north-west coast of Spitsbergen, touching at Reykjavik, Iceland, August 24, and returning to the base station at Greenport, Long Island, October 9, and to Brooklyn, New York, October $2 \mathrm{I}$. During this cruise the Carnegie was in command of $\mathrm{Mr}$. J. P. Ault. She is now being refitted for a longer cruise during $1915-16$, in southern latitudes $\left(50^{\circ}\right.$ to $\left.75^{\circ}\right)$, where magnetic observations require supplementing. NO. 2373 , VOL. 95]
An attempt at an ocean expedition into Hudson Bay was made under the charge of Mr. W. J. Peters during the past summer, but on account of unusual obstacles from ice this proved only partly successful. Entrance into the Bay with the auxiliary schooner George B. Cluett, chartered for this purpose from the Grenfell Association, was blocked until September 2, leaving less than a month's time available for surveys.

Determinations of magnetic elements on land have been continued in six parts of Africa, in as many States of South America, and in Australia, bringing the surveys of all these continental areas to a welladvanced stage.

With the end of the current year the Mount Wilson Solar Observatory, like most other departments of the institution, will have completed a first decade of its history. Quite appropriately, this establishment was founded at an epoch of maximum sun-spots, and a marked increase in solar activity during the past year furnishes similarly auspicious conditions for entrance into a sccond decade of research. But much more auspicious conditions are found in the extensive experience and in the effective equipment acquired along with the capital progress attained during this first decade. The most sanguine astronomer would have hesitated at the earlier epoch to predict that these latter conditions could be realised at the present epoch. Herein also is found a signal illustration of the superior effectiveness of establishments primarily designed for and exclusively devoted to research as compared with establishments in which research is a matter of secondary interest.

Progress in construction of the roo-inch telescope has been made as rapidly as could be expected in so formidable an undertaking. The delicate optical task of shaping the roo-inch mirror has been brought successfully by Mr. Ritchey to the stage of sphericity which precedes the final state of parabolisation. The difficulties due to distortion of the mass of the disc, referred to in previous reports, have been overcome, and other obstacles due to temperature inequalities in the optical room are likewise yielding to appropriate precautions. In the meantime, the foundations for this telescope have been completed, and the mounting and dome are expected to be ready for erection during the coming year. Several smaller parts and accessories for this instrument, requiring special exactness, are under construction at the shops of the observatory in Pasadena. Manv additions and improvements in the apparatus already installed at the observatory have been made. The 6o-foot tower telescope particularly, which was originally cheaply constructed in order to test the possible advantages of such a departure from earlier forms of telescopes, has been put in a state of efficiency comparable with that of the $\mathrm{I}_{5} \mathrm{O}-\mathrm{foot}$ tower telescope, leaving the latter free for the uses to which it is specially devoted. In these general improvements much attention has been given to rendering the plant on Mount Wilson more nearly fireproof. The mountain road has been repaired, widened, and strengthened in many parts in anticipation of the heavy traffic essential to transportation of the roo-inch telescope to its destination.

\section{UNIVERSITY AND EDUCATIONAL INTELLIGENCE.}

CAMBridge.-The Adams prize for $1913^{-14}$ has been awarded to Mr. G. I. Taylor, Smith's Prizeman in 1910. The subject selected was "The phenomena of the disturbed motion of fluids, including the resistances encountered by bodies moving through them." The value of the prize is about $25 \mathrm{ol}$. 